\title{
Music helps addicted patients to reduce negative emotions in everyday life
}

Stefan Gebhardt ${ }^{*}$, Markus Kunkel ${ }^{2}$ and Richard von Georgi ${ }^{3}$

*Correspondence: Stefan.Gebhardt@uni-marburg.de

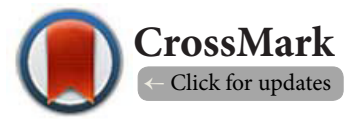

'Department of Psychiatry and Psychotherapy, University of Marburg, Marburg, Germany.

${ }^{2}$ Department of Music science and Music education, Justus-Liebig-University Giessen, Germany.

${ }^{3}$ Department of Music science and Music education, Justus-Liebig-Universität Giessen, Germany; International Psychoanalytic

University Berlin, Germany.

\begin{abstract}
Introduction: The study aimed to explore the impact of the use of music in the everyday life of those dependent on substance abuse.

Methods: A psychiatric population ( $\mathrm{n}=190 ; 111$ female; mean age of $37.4 \pm 13.3$ years) was examined using the IAAM (inventory for the assessment of activation and arousal modulation through music) to measure the situation-dependent everyday life use of music, the SKI (self-concept inventory) for personality dimensions and the GAF score (Global assessment of functioning). Group differences of patients with and without substance abuse were assessed.

$\underline{\text { Results: }}$ Substance abuse was identified in 28 patients (14.7\%). Patients of this group showed a lower functioning level $(p=0.045)$ and reported they listened more to music for relaxation $(p=0.018)$ and cognitive problem solving $(\mathrm{p}=0.047)$, more under the influence of psychotropic drugs $(\mathrm{p}<0.003)$ and-after the onset of the mental disorder-more to loud music $(\mathrm{p}=0.005)$ than patients without substance abuse $(\mathrm{n}=162)$.

Discussion and conclusion: Psychiatric patients with substance abuse use music particularly to reduce negative emotions compared to psychiatric patients without substance abuse. This result can be discussed on the basis of the reward system which is influenced by both psychotropic substances as well as by music. The results have a substantial relevant clinical impact and therapeutic conclusions have been drawn. Further studies are warranted.
\end{abstract}

Keywords: Music, emotion modulation, mental disorders, addiction disorders, cognition, arousal, reward system

\section{Introduction}

Since ancient times music has been a communication medium with probably the highest emotional influence on the human being, leading to great pleasure. It is therefore alleged to have a great impact on the reward system (see [1]). In this regard, music is closely related to psychotropic substances in the effect it has and the nearness to addiction disorders is striking. In fact, a multitude of musicians are known to have problems with substance abuse. At the same time, peer groups of adolescents often define themselves on the basis of music preferences as well as on the consumption of psychotropic substances [2-4]. The effects of psychotropic substances are specifically constituted in combination with music, e.g., in rave parties [5] and are well known to be associated with mental disorders. In a study on tobacco smoking in 152 high school and college students, a higher preference for music associated with anxiety and depressed mood was found among smokers [6].

In our previous studies strategies to modulate negative and positive emotions by music could be identified, as well as differences in reception behavior among diagnostic groups of mental disorders and in comparison to control groups [7-10]. Due to the particular impact of psychotropic substances on emotion modulation, the aim of the current study was to assess addiction-related aspects in music reception behavior in a psychiatric population. Given the cross-sectional design of this study, it is not possible to test a priori hypotheses; however, there were three main topics, which were explored in this study:

1. Activation and arousal modulation strategies with and 
Gebhardt et al. Research Journal of Drug Abuse 2014,

without the diagnosis of substance abuse.

2. Impact of personality dimensions and of the global functioning level.

3. Influence of further socio-demographic or specifically music-related parameters with respect to the onset of mental disorder.

\section{Methods \\ Subjects}

Of $n=190$ patients ( 111 female; mean age $37.4 \pm 13.3$ years, range 18-82 years) admitted to the Department of Psychiatry and Psychotherapy of the Philipps-University of Marburg/ Germany $n=12$ patients (6.3\%) had a diagnosis of psychoactive substance use (F1 group of ICD-10 [11]). The other patients suffered from affective disorders ( $F 3 ; n=66 ; 36.4 \%)$, neurotic, stress-related and somatoform disorders ( $F 4 ; n=46 ; 24.2 \%$ ), disorders of adult personality and behavior ( $F 6 ; n=34 ; 17.9 \%$ ), schizophrenia spectrum disorders ( $F 2 ; n=22 ; 12.2 \%)$, behavioral syndromes associated with physiological disturbances and physical factors (F5; $n=6 ; 3.2 \%)$, organic disorders F0 ( $n=3$; $1.6 \%)$ and disturbance of activity and attention in adulthood in one case (diagnosis of F9; $n=1 ; 0.5 \%$ ). For the current research question we separated the total study sample into two groups: the addiction disorder (AD) group and non-addiction disorder (NAD) group. The AD group consisted of 28 patients (14.7\%): 19 patients (10.0\%) showing a dependence syndrome as main diagnosis or as comorbidity $(n=7 ; 3.7 \%)$ as well as 9 patients with harmful use as comorbidity. The diagnoses of these patients were: dependence syndrome due to alcohol $(n=9 ; 4.7 \%)$, sedatives or hypnotics $(n=5 ; 2.6 \%)$, cannabinoids $(n=3 ; 1.6 \%)$ and due to multiple drug use $(n=2 ; 1.1 \%)$, as well as harmful use of alcohol $(n=3 ; 1.6 \%)$, cannabis $(n=3 ; 1.6 \%)$ and multiple substances $(n=3 ; 1.6 \%)$. Nicotine dependence as sole substance misuse was not included in the AD group due to the widespread prevalence. The 16 patients with substance abuse as comorbid disorder had diagnoses of the following ICD-10 diagnostic groups: F2 $(n=3), F 3(n=5), F 4(n=5), F 6$ $(n=3)$. Socio-demographic data are shown in Table 1. The AD group comprised significantly more male $(n=19)$ than female $(n=9)$ patients compared to the NAD group which had more female $(n=102)$ than male $(n=60)$ patients (Chi-Quadrat=9.3; $p=0.003$ ). Gender and age within the total sample did not correlate significantly.

Patients gave written informed consent; the study was approved by the Ethics Committee of the University of Marburg.

\section{Assessment and instruments}

The patients received self-assessment questionnaires. The "Inventory for the assessment of Activation and Arousal modulation through Music" (IAAM) with 62 items on a 5-pointscale showing high reliability and validity [12-15] was used to measure the situation-dependent everyday use of music according to the parameters Relaxation (RX), Cognitive Problem Solving (CP), Reduction of negative Activation (RA),
Table 1. Socio-demographic data of the AD (addiction disorder) and NAD (non-addiction disorder) group.

\begin{tabular}{|c|c|c|c|}
\hline \multicolumn{2}{|l|}{ Dependent variable } & \multicolumn{2}{|c|}{ Independent variable } \\
\hline & & $\begin{array}{l}\text { AD group } \\
(\mathrm{n}=28)\end{array}$ & $\begin{array}{l}\text { NAD group } \\
(n=162)\end{array}$ \\
\hline Age & Mean age & $35.1 \pm 10.4$ & $38.8 \pm 13.7$ \\
\hline Gender ${ }^{\star *}$ & $\begin{array}{l}\text { Male } \\
\text { Female }\end{array}$ & $\begin{array}{l}\mathrm{n}=19 \\
\mathrm{n}=9\end{array}$ & $\begin{array}{l}\mathrm{n}=60 \\
\mathrm{n}=102\end{array}$ \\
\hline Family status & $\begin{array}{l}\text { Married } \\
\text { Single } \\
\text { Divorced/Separated } \\
\text { Widowed } \\
\text { Missing } \mathrm{n}=5\end{array}$ & $\begin{array}{l}\mathrm{n}=3 \\
\mathrm{n}=18 \\
\mathrm{n}=4 \\
\mathrm{n}=2 \\
--\end{array}$ & $\begin{array}{l}\mathrm{n}=52 \\
\mathrm{n}=80 \\
\mathrm{n}=17 \\
\mathrm{n}=9 \\
--\end{array}$ \\
\hline Number of children & $\begin{array}{l}0 \\
1 \\
2 \\
3 \\
4 \\
\text { Missing } \mathrm{n}=8\end{array}$ & $\begin{array}{l}\mathrm{n}=19 \\
\mathrm{n}=4 \\
\mathrm{n}=2 \\
\mathrm{n}=3 \\
\mathrm{n}=0 \\
--\end{array}$ & $\begin{array}{l}\mathrm{n}=93 \\
\mathrm{n}=22 \\
\mathrm{n}=30 \\
\mathrm{n}=6 \\
\mathrm{n}=3 \\
--\end{array}$ \\
\hline $\begin{array}{l}\text { School leaving } \\
\text { examination }\end{array}$ & $\begin{array}{l}\text { No } \\
\text { Junior high school } \\
\text { Secondary school } \\
\text { Leaving certificate } \\
\text { High-school diploma } \\
\text { University degree } \\
\text { Missing n=2 }\end{array}$ & $\begin{array}{l}\mathrm{n}=0 \\
\mathrm{n}=6 \\
-- \\
\mathrm{n}=9 \\
\mathrm{n}=9 \\
\mathrm{n}=3 \\
--\end{array}$ & $\begin{array}{l}\mathrm{n}=2 \\
\mathrm{n}=42 \\
-- \\
\mathrm{n}=45 \\
\mathrm{n}=49 \\
\mathrm{n}=23 \\
--\end{array}$ \\
\hline Current profession & $\begin{array}{l}\text { Job } \\
\text { Jobless } \\
\text { Housewife/man } \\
\text { Pensioner } \\
\text { Pupil } \\
\text { Student } \\
\text { Trainee } \\
\text { Missing n=4 }\end{array}$ & $\begin{array}{l}\mathrm{n}=6 \\
\mathrm{n}=11 \\
\mathrm{n}=1 \\
\mathrm{n}=3 \\
\mathrm{n}=0 \\
\mathrm{n}=4 \\
\mathrm{n}=3 \\
--\end{array}$ & $\begin{array}{l}\mathrm{n}=59 \\
\mathrm{n}=26 \\
\mathrm{n}=19 \\
\mathrm{n}=14 \\
\mathrm{n}=2 \\
\mathrm{n}=32 \\
\mathrm{n}=6 \\
--\end{array}$ \\
\hline
\end{tabular}

${ }^{* *} \mathrm{p}<0.010$

Fun Seeking (FS) and Arousal Modulation (AM). Personality dimensions were assessed by means of the self-concept inventory (SKI [16]). The SKI is designed to register that part of the personality which results mainly from interpersonal interaction. The 5 scales, each containing 8 bipolar items on a 7-point-scale, cover the following dimensions with sufficient reliability coefficients (Cronbach's Alpha): egostrength vs. insecurity (E-I) (sense of personal and existential security together with the lack of feelings of anxiety; $a=0.79$ ), attractiveness vs. marginality (A-M) (self-assessment of own worth in social groups; $a=0.90)$, confidence vs. reserve ( $C$ R) (attachment capacity and intimacy; $a=0.85$ ), orderliness vs. insouciance (O-I) (degree of structuring in personal environment; $\alpha=0.78$ ) and enforcement vs. cooperation ( $E-C$ ) (self-assessment of assertiveness in social groups; $a=0.74$ ). The Global Assessment of Functioning scale (GAF [17]) was used to assess the global functioning of the patients. Another short questionnaire gathered data on musical socialization, subjective impressions on emotional modulation, substance abuse and the volume of music listened to and the duration of listening to music per day before and after the onset of 
the mental disorder. Furthermore, data on the psychiatric disorder were taken from the medical records.

\section{Statistical procedures}

As statistical procedures group differences between $A D$ and NAD patients were assessed by two-tailed Student's t-tests for continuous and two-tailed chi-quadrat-tests for dichotomous variables. In this exploratory study the term "significant" was used for results with a $p$-value of $\leq 0.05$. The data were analyzed using Statistical Package of the Social Sciences (SPSS 18.0 for Windows) software.

\section{Results}

\section{Group differences}

The investigation of group differences in IAAM/SKI scales and the GAF score revealed the following significant differences (see Table 2): Patients of the AD group showed higher values of RX and CP ( $p=0.018 / 0.047)$ as well as more confidence (or less reserve, respectively) ( $C-1 ; p=0.019)$ and a lower GAF $(p=0.045)$ than patients without substance abuse. The other IAAM/SKI scales showed no significant differences between these both groups.

The evaluation of the chi-quadrat-tests on categorical variables of the third questionnaire on specific items concerning music reception revealed the following results (see Table 3 ): Before and after the onset of a mental disorder patients of the AD group consumed more alcohol $(p=0.003 / p<0.001)$,

Table 2. Results on significant differences between addiction disorder (AD) group and non-addiction disorder (NAD) group in IAAM/SKI scales and the GAF score (global assessment of functioning).

\begin{tabular}{llllll}
\hline & AD group & NAD group & & & \\
\hline & Mean value \pm S.D. & Mean value \pm S.D. & T & Df & Significance \\
\hline RX & $26.9 \pm 9.3$ & $22.2 \pm 9.5$ & 2.40 & 165 & $\mathrm{p}=0.018$ \\
CP & $24.0 \pm 11.1$ & $20.0 \pm 9.1$ & 2.00 & 163 & $\mathrm{p}=0.047$ \\
C-R & $38.4 \pm 10.4$ & $33.0 \pm 11.0$ & 2.37 & 166 & $\mathrm{p}=0.019$ \\
GAF & $52.9 \pm 7.6$ & $57.1 \pm 10.4$ & 2.97 & 186 & $\mathrm{p}=0.045$ \\
\hline
\end{tabular}

RX: Relaxation; CP: Cognitive problem solving (both IAAM scales); C-R: Confidence vs. reserve (a SKI scale); GAF: Global assessment of functioning nicotine $(p=0.002 / p<0.001)$ and cannabis/cocaine/ecstasy ( $p=0.002 / p<0.001)$ while listening to music than patients of the NAD group. Moreover, AD patients listened more to loud music than NAD patients after (but not before) the onset of a mental disorder $(p=0.005)$.

$A D$ and NAD patients did not differ with respect to whether they had learned an instrument, were professional musicians, or to the role of music in their family, whether they considered themselves musical and whether music had a certain impact in their lives. Both in the time before as well as after the onset of a mental disorder AD and NAD patients did not differ regarding the following variables: choosing that music which helps for mood modulation, preferring text or music, listening to music more actively vs. hearing it in the background, duration of music reception, consumption of caffeine.

\section{Discussion}

Patients with drug abuse do not differ from other patients with other psychiatric disorders with respect to musical socialization or to the role they attribute to music in their life. Before and after the onset of a mental disorder AD patients consumed more alcohol, nicotine or cannabis/cocaine/ecstasy while listening to music than did NAD patients. However, AD patients seem to draw more strongly on music for relaxation and cognitive problem solving than patients with other mental disorders. Interestingly, AD patients do not use music for fun seeking in contrast to healthy individuals [8].

We interpret these results that AD patients, who also showed more confidence and less reserve, respectively (C-R), than NAD patients, might have an intensified approach to music as a very strong emotional stimulus in the same way as they use psychotropic substances as a strong stimulus. In this context it has to be mentioned that the personality dimension of more confidence and less reserve, acquired through the self-assessment questionnaire, might already reflect the psychological conditions under the influence of psychotropic substances; e.g., patients might feel more self-confident when they have consumed alcohol or tranquilizers.

By means of positron emission tomography Blood \& Zatorre [18] observed that the highly pleasurable experience of "chills" ("shivers-down-the-spine") is associated with cerebral blood flow increases and decreases in brain regions thought to be

Table 3. Significant differences between the addiction disorder (AD) group and the non-addiction disorder (NAD) group in categorical variables.

\begin{tabular}{|c|c|c|c|c|c|}
\hline & & $\begin{array}{l}\text { AD group }(\mathrm{n}=28) \\
\mathrm{n} \text { (yes/no) }\end{array}$ & $\begin{array}{l}\text { NAD group }(\mathrm{n}=162) \\
\mathrm{n} \text { (yes/no) }\end{array}$ & $\begin{array}{l}\text { Missing data } \\
\text { (n) }\end{array}$ & $\begin{array}{l}\text { Significance of } \\
\text { difference }\end{array}$ \\
\hline $\begin{array}{l}\text { Consuming drugs while } \\
\text { listening to music }\end{array}$ & $\begin{array}{l}\text { Alcohol } \\
\text { Nicotine } \\
\text { Cannabis, cocaine, ecstasy }\end{array}$ & $\begin{array}{l}11 / 17 \\
21 / 7 \\
7 / 21\end{array}$ & $\begin{array}{l}21 / 131 \\
64 / 89 \\
7 / 146\end{array}$ & $\begin{array}{l}10 \\
9 \\
9\end{array}$ & $\begin{array}{l}\mathrm{p}=0.003 \\
\mathrm{p}=0.002 \\
\mathrm{p}=0.002\end{array}$ \\
\hline $\begin{array}{l}\text { Consuming drugs while } \\
\text { listening to music }\end{array}$ & $\begin{array}{l}\text { Alcohol } \\
\text { Nicotine } \\
\text { Cannabis, cocaine, ecstasy }\end{array}$ & $\begin{array}{l}12 / 16 \\
20 / 8 \\
6 / 22\end{array}$ & $\begin{array}{l}18 / 30 \\
49 / 99 \\
2 / 146\end{array}$ & $\begin{array}{l}14 \\
14 \\
14\end{array}$ & $\begin{array}{l}\mathrm{n}<0.001 \\
\mathrm{n}<0.001 \\
\mathrm{n}<0.001\end{array}$ \\
\hline Loud music $^{\mathrm{a}}$ & Listening to loud music & $14 / 13$ & $33 / 103$ & 27 & $\mathrm{p}=0.005$ \\
\hline
\end{tabular}

a: after onset of mental disorder; b: before onset of mental disorder 
involved in reward, emotion and arousal, namely the ventral striatum, midbrain, amygdala, orbitofrontal cortex, and ventral medial prefrontal cortex. A MRI study underlined these findings as it showed a greater activation in the medial orbital frontal cortex, nucleus accumbens and ventral striatum as regions of the reward system in healthy controls compared to depressed patients and in association with favorite music ${ }^{1}$. Hereby, pleasure was positively correlated with activity in the left medial prefrontal cortex and negatively correlated with the middle temporal cortex and globus pallidus' ${ }^{1}$. The reward system is strongly associated with the opiate system which is connected to pain. In a recent study we were able to show a significant reduction of pain ratings in patients with depressive disorders under the influence of music [19].

Another explanation for the enhanced emotion modulation strategies by means of music in patients with substance abuse could be the general behavior pattern in this diagnostic group, i.e., craving for high amounts of psychotropic effects compared to patients suffering from other mental disorders. This would imply that patients with substance abuse do not substantially differ in their emotion modulation strategies from other patients, merely to a more excessive extent. Also increased loudness after the onset of the mental disorder might reflect the impetus of enhancing emotion modulation strategies in order to reach a new equilibrium. The need for this strategy might be strong, because patients with substance abuse were rated on a lower global functioning level (GAF) than patients without addictive tendencies.

As a consequence, patients with addiction disorder could profit from music therapy. Accordingly, results of a prospective non-naturalistic and non-randomized pilot study without a control group suggest that music therapy in severely impaired patients with co-occurring mental illness and addiction is beneficial [20].

\section{Conclusions}

To our knowledge this is the first study to compare patients with substance abuse and patients with other mental disorders with respect to the use of music in the everyday life. The study represents a naturalistic examination, suggesting that patients with substance abuse listen more to music for relaxation and cognitive problem solving than patients with other mental disorders. During their illness they listened to louder music in combination with consuming psychotropic substances.

\section{Limitations and strengths}

One limitation is the cross-sectional design, instead of a prospective, controlled one. Therefore, causal relationships cannot be inferred and the the listed $p$-values are of an explorative nature. Another limitation is the imbalance of the $A D$ and the NAD group. However, the data represent real world conditions and allow the assessment of group differences within a psychiatric population. The strength of this study is that instruments used have been well evaluated allowing now for an empirical approach on the basis of an emotional modulation concept.

\section{List of abbreviations}

AD: Addiction disorder

A-M: Attractiveness vs. marginality

AM: Arousal modulation

C-R: Confidence vs. reserve

CP: Cognitive problem solving

FS: Fun seeking

GAF: Global assessment of functioning

E-C: Enforcement vs. cooperation

E-I: Ego-strength vs. insecurity

IAAM: Inventory for the assessment of activation

and arousal modulation through music

ICD: International classification of disorders

NAD: Non-addiction disorder

O-I: Orderliness vs. insouciance

RA: Reduction of negative activation

$\mathrm{RX}$ : Relaxation

SKI: Self-concept inventory

Competing interests

The authors declare that they have no competing interests.

Authors' contributions

\begin{tabular}{|l|c|c|c|}
\hline Authors' contributions & SG & MK & RVG \\
\hline Research concept and design & $\checkmark$ & $\checkmark$ & $\checkmark$ \\
\hline Collection and/or assembly of data & $\checkmark$ & $\checkmark$ & $\checkmark$ \\
\hline Data analysis and interpretation & $\checkmark$ & $\checkmark$ & $\checkmark$ \\
\hline Writing the article & $\checkmark$ & -- & $\checkmark$ \\
\hline Critical revision of the article & $\checkmark$ & $\checkmark$ & $\checkmark$ \\
\hline Final approval of article & $\checkmark$ & $\checkmark$ & $\checkmark$ \\
\hline Statistical analysis & $\checkmark$ & -- & $\checkmark$ \\
\hline
\end{tabular}

\section{Acknowledgement and funding}

We thank Prof. Jürgen-Christian Krieg for having supported this study on the patients of the Department of Psychiatry and Psychotherapy, University of Marburg/Germany and for his helpful, critical comments. There was no funding of the study.

\section{Publication history}

Editor: Narayan G. Bhat, The University of Texas, USA.

Received: 19-Aug-2014 Final Revised: 26-Sep-2014

Accepted: 29-Oct-2014 Published: 05-Nov-2014

\section{References}

1. Osuch EA, Bluhm RL, Williamson PC, Theberge J, Densmore M and Neufeld RW. Brain activation to favorite music in healthy controls and depressed patients. Neuroreport. 2009; 20:1204-8. | Article | PubMed

2. Mulder J, Ter Bogt TF, Raaijmakers QA, Nic Gabhainn S, Monshouwer K and Vollebergh WA. Is it the music? Peer substance use as a mediator of the link between music preferences and adolescent substance use. $J$ Adolesc. 2010; 33:387-94. | Article | PubMed

3. Mulder J, Ter Bogt TF, Raaijmakers QA, Gabhainn SN, Monshouwer K and Vollebergh WA. The soundtrack of substance use: music preference and adolescent smoking and drinking. Subst Use Misuse. 2009; 44:514-31. | Article | PubMed

4. Mulder J, Ter Bogt TF, Raaijmakers QAW, Gabhainn SN and Sikkema P. From death metal to R\&B? Consistency of music preferences among 
Dutch adolescents and young adults. Psychology of music. 2010; 38:6783.

5. Nencini P. The shaman and the rave party: social pharmacology of ecstasy. Subst Use Misuse. 2002; 37:923-39. | Article | PubMed

6. Posluszna J, Burtowy A and Palusinski R. Music preferences and tobacco smoking. Psychol Rep. 2004; 94:240-2. | Article | PubMed

7. Gebhardt $S$ and von Georgi R. Music, mental disorder and emotional reception behavior. Music Therapy Today. 2007; 3. | Pdf

8. Gebhardt S, Kunkel M and von Georgi R. Emotion modulation in psychiatric patients through music. Music Percept. 2014; 31:485-493. Article

9. von Georgi R, Grant P, von Georgi S and Gebhardt S. Personality, emotion and the use of music in everyday live: Measurement, theory and neurophysiological aspects of a missing link. First studies with the IAAM. Tönning, Marburg, Lübeck: Der Andere Verlag. 2006.

10. von Georgi R, Göbel $M$ and Gebhardt S. Emotion modulation by means of music and coping behaviour. In: Haas R, Brandes V (Eds.), Music that works. Wien, New-York: Springer Verlag. 2009; 301-19. | Book

11. Dilling $\mathrm{H}$, Mombour $\mathrm{W}$ and Schmidt $\mathrm{MH}$. Internationale Klassifikation psychischer Störungen. ICD-10 Kapitel V (F). Bern: Huber Hans. 2013. | Book

12. von Georgi R. Das Inventar zur Messung der Aktivations- und ArousalModulation mittels Musik (IAAM). In: Schramm H (Ed.), Medien und Kommunikationswissenschaft - Sonderband 1, Musik und Medien“. Baden-Baden: Nomos. 2007; 138-156. | Book

13. von Georgi R, Abou Seif A, Grant P and Beckmann D. Application of music for activation and arousal modulation in everyday life. Abstract Jahrestagung der Deutschen Gesellschaft für Musikpsychologie. 2005.

14. von Georgi R, Cimbal K and Von Georgi S. Aktivations- und ArousalModulation mittels Musik im Alltag und deren Beziehungen zu musikalischen Präferenzen, Persönlichkeit und Gesundheit. In: Auhagen W, Bullerjahn C, Höge H (Eds.), Musikpsychologie. Jahrbuch der Deutschen Gesellschaft für Musikpsychologie. Göttingen: Hogrefe. 2004; 141-83.

15. von Georgi R, Grant P, Adjomand G and Gebhardt S. Personality, musical preference and health: First results of the validation of the IAAM. Abstract - Jahrestagung der Deutschen Gesellschaft für Musikpsychologi. 2005. | Article

16. von Georgi R and Beckmann D. Selbstkonzept Inventar. Bern, Göttingen, Toronto, Seattle: Hans Huber Verlag, 2004. | Book

17. American Psychiatric Association (APA). Diagnostic and statistical manual of mental disorders, 4th ed., revised (DSM-IV-TR). Washington, DC: American Psychiatric Press. 2000.

18. Blood AJ and Zatorre RJ. Intensely pleasurable responses to music correlate with activity in brain regions implicated in reward and emotion. Proc Natl Acad Sci U S A. 2001; 98:11818-23. | Article | PubMed Abstract | PubMed Full Text

19. Gebhardt S, Huber MT and von Georgi R. Effects of music on tonic heat pain in depression - a preliminary investigation. Pain Relief Rep. 2014. I Website

20. Ross S, Cidambi I, Dermatis H, Weinstein J, Ziedonis D, Roth S and Galanter M. Music therapy: a novel motivational approach for dually diagnosed patients. J Addict Dis. 2008; 27:41-53. | Article | PubMed

Citation:

Gebhardt S, Kunkel M and von Georgi R. Music helps addicted patients to reduce negative emotions in everyday life. Res J Drug Abuse. 2014; 1:1.

http://dx.doi.org/10.7243/2057-3111-1-1 